\title{
EFFECT OF MATRIX CRACKING ON MECHANICAL PROPERTIES IN FRP ANGLE-PLY LAMINATES
}

\author{
M.J. Mohammad Fikry ${ }^{1}$, Shinji Ogihara ${ }^{2}$ and Vladimir Vinogradov ${ }^{3}$ \\ ${ }^{1}$ Department of Mechanical Engineering, Graduate School of Science and Technology, \\ Tokyo University of Science, 2641 Yamazaki, Noda-shi, Chiba-ken, Japan \\ Email:7517662@ed.tus.ac.jp \\ ${ }^{2}$ Department of Mechanical Engineering, Faculty of Science and Technology, \\ Tokyo University of Science, 2641 Yamazaki, Noda-shi, Chiba-ken, Japan \\ Email: ogihara@rs.noda.tus.ac.jp \\ ${ }^{3}$ School of Engineering, Newcastle University, Newcastle upon Tyne, NE1 7RU, UK \\ Email: vladimir.vinogradov@newcastle.ac.uk
}

Keywords: composites, laminate, stiffness reduction, artificial cracks, crack density, damage behavior

\begin{abstract}
Fiber Reinforced Polymer laminates (FRP) have properties, which are highly dependent on the ply fiber orientations and which can be designed for optimum laminate performance. The purpose of this study is to investigate effect of matrix cracking on the mechanical properties of angle-ply FRP laminates. Carbon and glass fiber reinforced polymer laminates (CFRP and GFRP) are tested. The laminates with layups $\left[\theta_{\mathrm{m}}{ }^{(2)} / \theta_{\mathrm{n}}{ }^{(1)}\right]_{\mathrm{s}}$ cured by using autoclave method are loaded monotonically and cyclically to obtain their mechanical properties and the effect of matrix cracks on the properties. Some of the effects include reduction of laminates' stiffness and residual strains after unloading. In order to obtain higher crack densities in specimens, artificial cracks method was introduced in this study, where notches were made at the edges of some specimens before tested in tension. The measured stiffness reduction as a function of the crack density is compared to an analytical prediction for cracked angle-ply laminates based on a variational stress analysis. The experimental results for stiffness reduction agree well with the analytical results. Understanding the behavior of damaged cross-ply and simple angle-ply laminates is of high importance for prediction of damage effects on laminates with more complex configuration, e.g. with quasi-isotropic layups.
\end{abstract}

\section{Introduction}

Fiber Reinforced Plastics (FRP) are used in many industries, such as aeronautical, automotive, construction, etc. While many designs, especially in aeronautical applications, aim at composite structures made of quasi-isotropic material, various stacking sequences can be designed for a specific composite structural element by modifying the distribution of ply orientations through the laminate thickness. With different combinations of fiber orientations, ply thicknesses and stacking sequences that can by suggested by the designers, understanding and characterization of damage formation and its effects on the laminate effective properties can be quite complicated. However, quite often these complex layups can be considered as an assembly of two main types of laminates, namely 'cross-ply' laminates, with fiber configuration of $0^{\circ}$ and $90^{\circ}$, and 'angle-ply' with the generic layup of $\left[\theta_{\mathrm{m}}{ }^{(2)} / \theta_{\mathrm{n}}{ }^{(1)}\right]_{\mathrm{s}}$. Understanding the basic damage behavior and changes in these two types of laminates due to damage can be a step in understanding laminates with more complex configuration.

Many damage modes can be observed in laminates, such as transverse cracking, delamination, fiber fracture, longitudinal splitting, etc. Usually during tensile loading, cross-ply and angle-ply laminates would initially demonstrate formation of matrix intralaminar cracks in the most off-axis plies, which 
normally originate from the free edges, and propagated in the width direction of the coupon. These cracks lead to reduction of the laminate stiffness, residual strains after unloading, and other phenomena. The main aim of the present study is to investigate the mechanical properties, damage formation and its effect on the mechanical properties of angle-ply FRP laminates. Laminates with cross-ply and unbalanced angle-ply stacking sequences $\left[\theta_{\mathrm{m}}^{(2)} / \theta_{\mathrm{n}}^{(1)}\right]_{\mathrm{s}}$ prepared from two different CFRP prepregs and one GFRP prepreg are studied.

\section{Methods and Materials}

\subsection{Specimen}

The materials used in this study is shown in Table 1. The prepregs are stacked according to the stacking sequences shown in Table 2 and cured in an autoclave at temperature of 130 degree Celsius and pressure of 0.2 MPa. The specimen's measurements are shown in Figure 1.

Table 1. Type of materials.

\begin{tabular}{cccc}
\hline & CFRP[1] & CFRP[2] & GFRP \\
\cline { 2 - 4 } & $\begin{array}{c}\text { T700SC/2500, } \\
\text { Torayca }\end{array}$ & T700SC/2592, Torayca & $\begin{array}{c}\text { GE352G135SB, Mitsubishi } \\
\text { Rayon }\end{array}$ \\
\hline $\begin{array}{c}\text { Ply } \\
\text { thickness }\end{array}$ & $0.05 \mathrm{~mm}$ & $0.15 \mathrm{~mm}$ & $0.101 \mathrm{~mm}$ \\
\hline Type & & Prepreg (preimpregnated composite fiber) \\
\hline
\end{tabular}

Table 2. Laminate structures and thicknesses.

\begin{tabular}{lll}
\hline Materials & Laminate structures & Thickness $(\mathrm{mm})$ \\
\hline \multirow{2}{*}{ CFRP [1] (T700SC/2500) } & {$\left[0_{3} / 90_{24} / 0_{3}\right],\left[0_{3} / 75_{24} / 0_{3}\right],\left[0_{3} / 45_{24} / 0_{3}\right]$} & 1.50 \\
\cline { 2 - 3 } & {$\left[0_{3} / 90_{36} / 0_{3}\right],\left[0_{3} / 75_{36} / 0_{3}\right],\left[0_{3} / 45_{36} / 0_{3}\right]$} & 2.10 \\
\hline \multirow{2}{*}{ CFRP [2] (T700SC/2592) } & {$\left[0 / 90_{8} / 0\right],\left[0 / 60_{8} / 0\right],\left[0 / 45_{8} / 0\right]$} & 1.47 \\
\cline { 2 - 3 } GFRP (GE352G135SB) & {$\left[0 / 90_{12} / 0\right],\left[0 / 60_{12} / 0\right],\left[0 / 45_{12} / 0\right]$} & 2.06 \\
\cline { 2 - 3 } & {$\left[0_{3} / 90_{12} / 0_{3}\right]$} & 1.80 \\
\cline { 2 - 3 } & {$\left[0_{3} / 90_{24} / 0_{3}\right],\left[0_{3} / 75_{24} / 0_{3}\right]$} & 3.00 \\
\hline & {$\left[-15_{3} / 75_{24} /-15_{3}\right],\left[0_{3} / 60_{24} / 0_{3}\right]$} & 3.00 \\
\hline
\end{tabular}

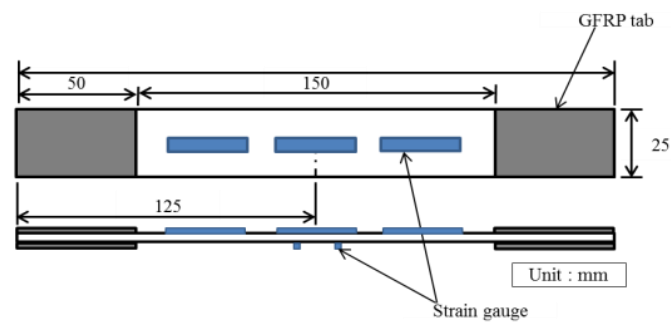

Figure 1. Specimen's measurement.

\subsection{Artificial cracks}

In contrast to cross-ply laminates, crack formation in angle-ply laminate requires significantly higher tensile loads due to the higher material stiffness. In order to increase the range of attained cracks densities, artificial crack method is introduced in this study when notches are formed at the both edges of the specimen by using a knife before it is pulled in a tensile test machine with cross head speed of $1 \mathrm{~mm} / \mathrm{min}$ to a specific load. Then the specimen is unloaded back to zero and the notched edges were cut by using composite material cutting machine (AC-300CF, Maruto Testing Machine) at $\pm 5 \mathrm{~mm}$ 
from the edges. To detect the artificial cracks induced, observation in an X-ray machine was carried out before it was tested in tension.

\subsection{Tensile tests and measurement}

Two types of experiments were carried out using Tensilon RTF-1350 A\&D tensile test machine: monotonic and loading-unloading tensile tests. Both of the experiments were performed with the cross head displacement speed of $1[\mathrm{~mm} / \mathrm{min}]$. The mechanical properties obtained from monotonic tensile test are tensile stress, longitudinal strain, transverse strain, the Young's modulus and Poisson's ratio. The loading-unloading tests were performed to investigate the mechanical properties affected by crack formation. For CFRP laminates, as the laminates are opaque, crack observation was done by using Xray, while for semi-transparent GFRP laminates, cracks were observed in-situ using a DSLR camera. Strain gauges were used to measure strains in the loaded and unloaded laminates. For more accurate strain readings, three uniaxial strain gauges were stacked in the loading direction. In this study, the crack density is defined as the number of cracks penetrated in the width direction over the length of strain gauges.

\section{Results and Discussions}

\subsection{Monotonic tensile test}

Strain gauges were attached in both the longitudinal and transverse directions for strain measurements in both the directions. The Young's modulus of every laminates was calculated at small strains of $0.1 \sim 0.3 \%$ when no cracks are typically formed. Nonlinearity of the stress-strain curves is correlated with the formation of cracks.

Figure 2 shows the stress-strain curves for CFRP[1] specimens: (a) $\left[0_{3} / 90_{24} / 0_{3}\right]$ and $\left[0_{3} / 90_{36} / 0_{3}\right]$, (b) $\left[0_{3} / 75_{24} / 0_{3}\right]$ and $\left[0_{3} / 75_{36} / 0_{3}\right]$, and (c) $\left[0_{3} / 45_{24} / 0_{3}\right]$ and $\left[0_{3} / 45_{36} / 0_{3}\right]$ laminates. Comparison of CFRP laminates with $90^{\circ}$ ply of different thicknesses indicates that the laminate with the thicker transverse ply fail at lower stress than the laminate with the thinner transverse ply. Similar behavior can be observed in the angle-ply laminates where thinner laminates showed higher stiffness and strength, as can be seen in Figure 2(b \& c).

For laminates with the same number of plies and the off-axis angle decreasing from $90^{\circ}$ to $45^{\circ}$, there are no remarkable differences in the Young's modulus. The Poisson's ratio, however, increases significantly as the off-axis angle decreases, as would be expected, since the contribution of the midply matrix to strain in the transverse direction increases. These results for the Young's modulus and Poisson's ratio are in agreement with the Classical Laminate Theory. It can also be observed that variation of the off-axis angle has a marginal effect on the tensile strength of the laminates.

(a)

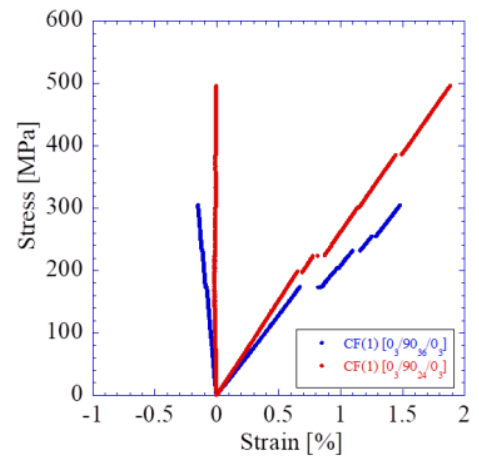

(b)

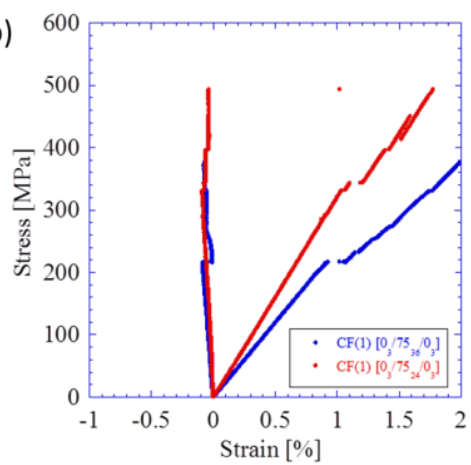

(c)

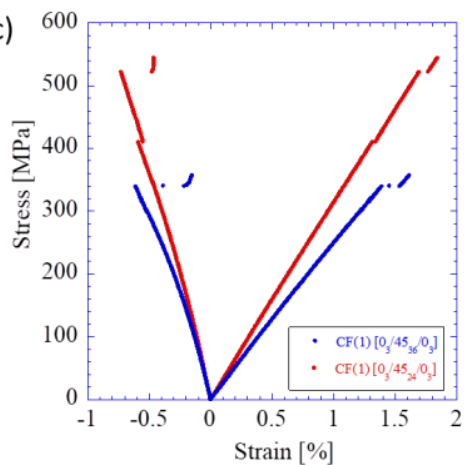

Figure 2. Strain-stress curve for CFRP[1] laminates with different orientation of the off-axis ply: (a) 90, (b) 75 and (c) $45^{\circ}$. 


\subsection{Loading-unloading tensile test}

Nonlinearity in the stress-strain curve obtained from monotonic tensile loading is mainly associated with formation of new cracks in the laminate. Once new cracks have formed, subsequent unloading follows a new linear stress-strain relationship, which reflects the effect of the formed cracks on the properties of the laminate. Therefore, unloading that does not induce additional damage in the laminate allows to observe the effects of damage in a more clear way.

Figure 3 shows the stress-strain curves recorded during cyclic loading for (a) CFRP $[1]\left[0_{3} / 75_{36} / 0_{3}\right]$ and (b) CFRP 2$]\left[0 / 60_{8} / 0\right]$ laminate. It can be seen that the gradients of stress-strain curve gradually decrease with every cycle due to a decrease in stiffness of the laminates. The stiffness was calculated at strain of $0.1 \% \sim 0.3 \%, 0.2 \% \sim 0.4 \%$ or $0.3 \sim 0.5 \%$ following formation of new cracks at every cycle. The figure also demonstrate existence and a gradual increase in residual strains as the laminates are unloaded back to zero stress at the end of each loading-unloading cycle. This is related to relief of curing stresses due to formation of intralaminar cracks. From the result for laminates with different thickness of off-axis plies, nonlinearity associated with onset of cracking is observed at higher strains in laminates with thinner off-axis plies. Similar results were obtained for the laminate configurations that have off-axis angle of $45^{\circ}, 60^{\circ}$ and $90^{\circ}$ for all CFRP[1], CFRP[2] and GFRP. Laminates with lower off-axis angles, such as $45^{\circ}$ or $60^{\circ}$, started to show nonlinearity at a higher strain (Figure 3(b)). In laminates of the same thickness the strain of initial nonlinearity increases as the off-axis angle changes from $90^{\circ}$ to $45^{\circ}$. Therefore, the changes in off-axis angle have a significant effect on the cracking onset strains.

(a)

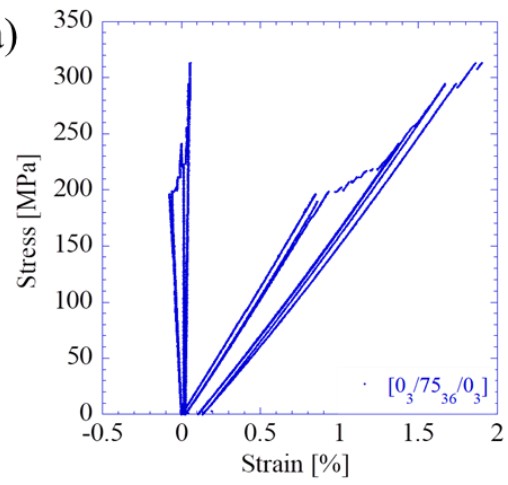

(b)

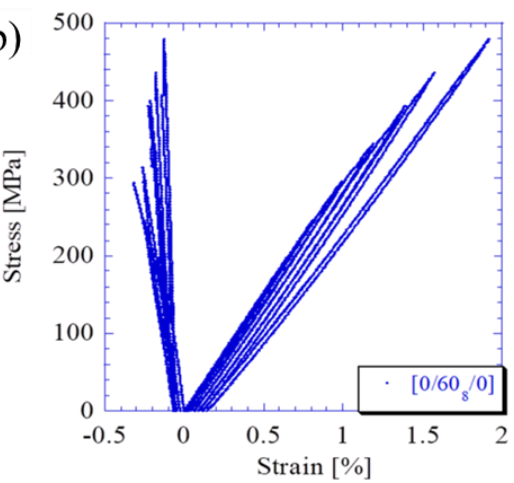

Figure 3. Strain-stress curve for loading-unloading tensile test: (a) CFRP $[1]\left[0_{3} / 75_{36} / 0_{3}\right]$ (b) CFRP 2$]\left[0 / 60_{8} / 0\right]$ laminate.

\subsection{Crack observation}

For CFRP[2] cross-ply [0/90 $12 / 0],\left[0 / 90_{8} / 0\right.$ ] and all CFRP[1] laminates, X-ray images were taken after unloading and removing from the tensile test machine, followed by remounting the specimens in the machine. For CFRP 2$]\left[0 / 60_{12} / 0\right],\left[0 / 60_{8} / 0\right],\left[0 / 45_{12} / 0\right]$ and $\left[0 / 45_{8} / 0\right]$ laminates, the X-ray images were taken after the artificial notches were removed. For GFRP laminates, due to its semi-permanent properties, cracks formation can be observed in real-time, tracing the crack density-strain relationship can be investigated. The cracks were observed and counted at specific area on the specimen which is along the length of strain gauge.

\section{(a) CFRP laminates}

Figure 4 shows X-ray images of CFRP $[1]\left[0_{3} / 75_{24} / 0_{3}\right]$ laminates after a loading-unloading tensile test. Initially at lower stress and strain, the results showed that most of the cracks were formed at the edges of the laminates without penetrated through the width of the coupons. As the applied strain increases, more tunneling cracks propagate through to the other edge of the coupon. Comparison of crack formation in laminates of different thicknesses indicates that crack initiation at the coupon edges occur 
at lower strains in thicker laminates. Both crack propagation in the width direction and the rate of new crack formation is slower in the thicker laminates. For laminates with different off-axis ply angle, decrease from $90^{\circ}$ to $45^{\circ}$ makes crack formation more effort demanding. For example, in laminates of off-axis angle of $45^{\circ}$, none of the edge cracks propagated entirely through the coupon width. Similar results were obtained for CFRP[2] laminates.

(a)

Loading direction

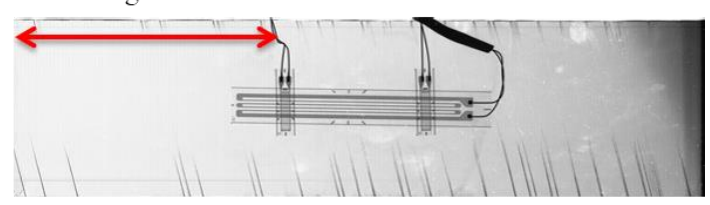

(b)

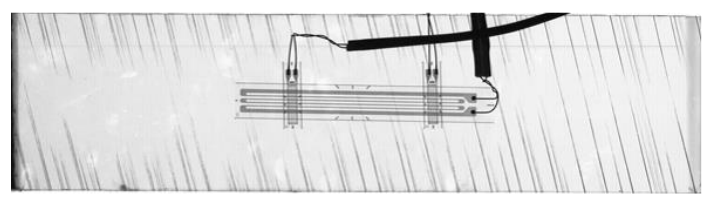

(c)

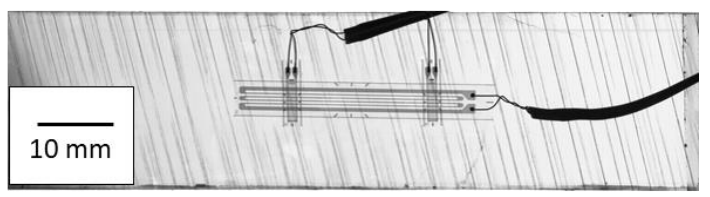

Figure 4. X-ray images of CFRP $[1]\left[0_{3} / 75_{24} / 0_{3}\right]$ laminate

(a) $\sigma=300[\mathrm{MPa}] \varepsilon=1.10[\%]$, (b) $\sigma=340[\mathrm{MPa}] \varepsilon=1.31[\%]$, (c) $\sigma=440[\mathrm{MPa}] \varepsilon=1.75[\%]$.

\section{(b) GFRP laminates}

In contrast to the cracking processes in CFRP laminates described above, cracks in GFRP laminates crossed the entire width of the laminate instantaneously. Cracks in GFRP laminates also formed at a lower stress and strain compared to CFRP laminates. Since GFRP laminates are transparent, new crack formation can be observed in-situ, while recording the corresponding values of applied strain. Figure 5 shows snapshots of a angle-ply coupon at different stress/strain levels, demonstrating increasing crack density with the applied strain. The laminate with layup $\left[0_{3} / 75_{24} / 0_{3}\right]$ showed gradually increasing crack density with increasing applies strain. Comparison of all laminate configurations indicates that fewer cracks form in laminates with smaller angles of the off-axis plies at the same applied strain.

(a)

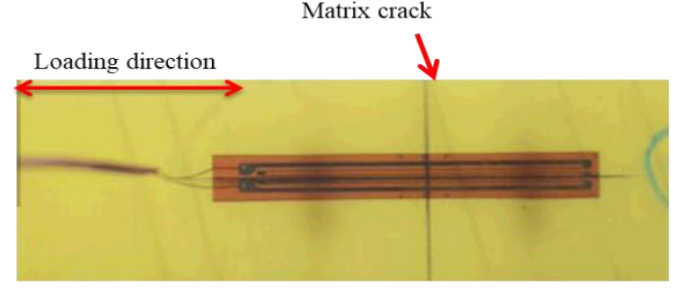

(b)

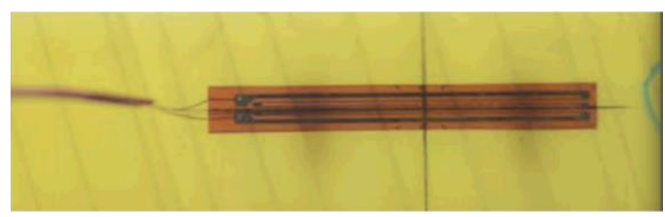

(c)

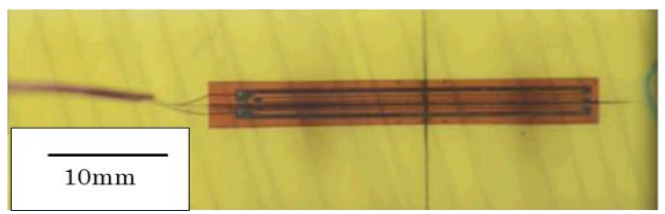

Figure 5. X-ray images of GFRP $\left[0_{3} / 75_{24} / 0_{3}\right]$ laminate

(a) $\sigma=160[\mathrm{MPa}] \varepsilon=1.47[\%]$, (b) $\sigma=180[\mathrm{MPa}] \varepsilon=1.85[\%]$, (c) $\sigma=200[\mathrm{MPa}] \varepsilon=2.36[\%]$. 


\subsection{Stiffness reduction due to matrix cracking and comparison to variational analysis}

Stiffness reduction is typically presented by normalizing the stiffness of the cracked laminate by the stiffness of the virgin laminate. Crack density can be defined as the total length of cracks propagated in the off-axis ply direction within the observation area divided by the area, or alternatively, the crack density is reciprocal of the average (shortest) distance between adjacent cracks.

Figures 6 and 7 show the results for stiffness reduction vs crack density obtained experimentally and analytically for CFRP[2] and GFRP. The experimental data represents results for two or more laminate specimens tested in loading-unloading, as well as those with artificially induced cracks. The analytical curves represent the results of a variational analysis. For the layups in the present experimental study, the variational analysis of Vinogradov and Hashin (2010) is the most suitable, as it considers laminates of the type $\left[\theta_{\mathrm{m}}^{(2)} / \theta_{\mathrm{n}}^{(1)}\right]_{\mathrm{s}}$. However, following the original assumptions of Hashin (1986), the method assumes a piece-wise constant distribution of stresses in the thickness direction, which for some, especially thick laminates, tends to underestimate the Young's modulus, when compared to the experimental data presented here. The more general variational approach of Vinogradov (2015), which is used herein, assumes a linear stress distribution in the thickness direction and allows ply refinement, when plies can be subdivided into several sub-plies, leading to a more accurate description of the stress field, and consequently, a better estimate for the effective Young's modulus.

As can be seen in all of the figures, for all laminate layups and materials, the differences in stiffness reduction of the thin and thick laminates can be seen quite distinctively, when higher stiffness reduction is observed in the thicker laminates with the same off-axis ply orientation. At the same time, laminates with $0^{\circ}$ outer ply and the same thickness show a marginal effect of the middle ply orientation on the normalized Young's modulus, e.g., compare laminates with 8 mid-ply laminae and different orientations (upper curves) in Figures 6. In Figure 6(a), experimental data for an additional CFRP[2] laminate with layup [-15/75 $12 /-15]$ is included, which has not been mentioned in the previous sections. It can be seen that rotation of the cross-ply $\left[0 / 90_{12} / 0\right]$ by $15^{\circ}$ leads to dramatic differences in the normalized stiffness reduction rates. Much smaller differences are predicted analytically for rotation of GFRP $\left[0_{3} / 90_{24} / 0_{3}\right]$ by $-15^{\circ}$ to form $\left[-15_{3} / 75_{24} /-15_{3}\right]$, as shown in Figures 7 (a) and 7(b), however, as described above, this laminate failed after just one crack has formed within the observation zone.

(a)

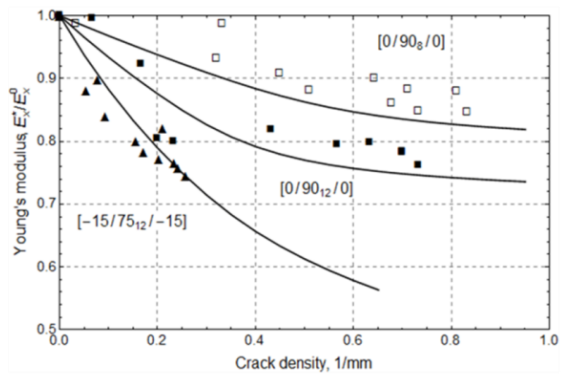

(b)

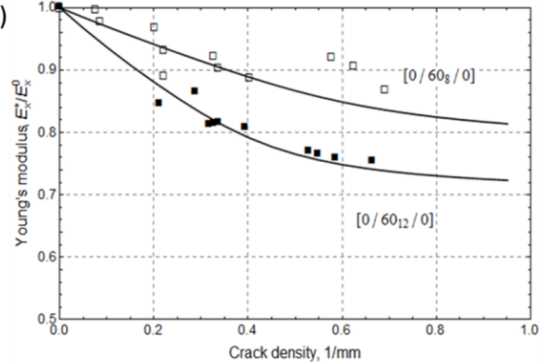

(c)

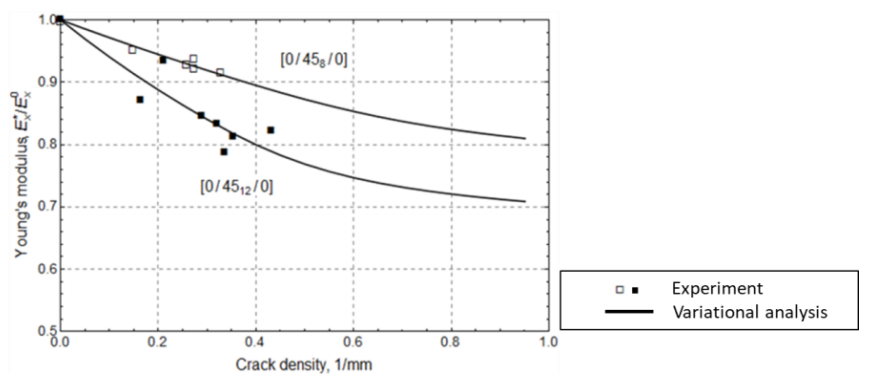

Figure 6. Stiffness reduction-crack density relationship of CFRP[2] laminates. 
(a)

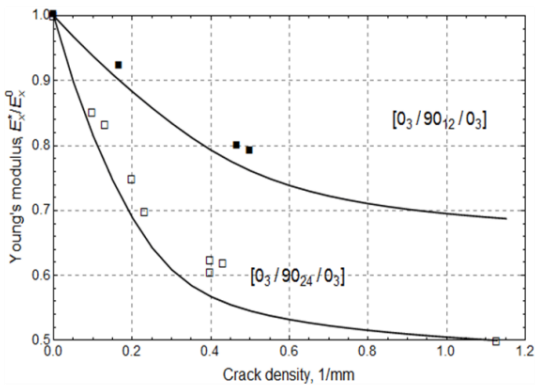

(b)

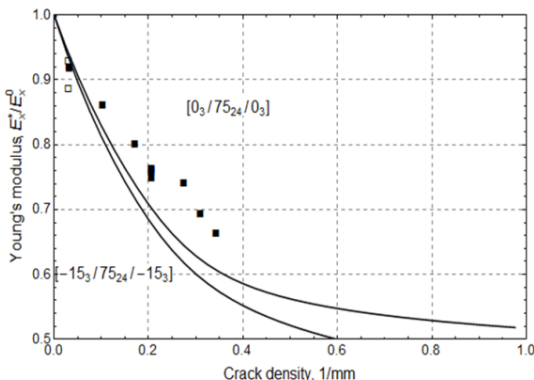

(c)

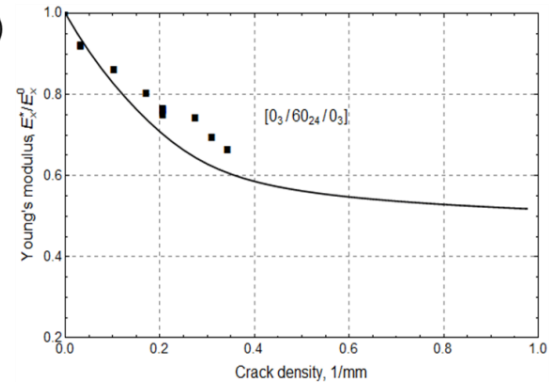

Figure 7. Stiffness reduction-crack density relationship of GFRP laminates.

In view of the fact that the variational analysis provides the lower bound for stiffness reduction and crack density relation, the analytical and experimental results for the studied laminates are in good agreement, as most of the experimental data points stay on or slightly above the analytical curves. However, there are several ocasions where experimental data are lower than the analytical prediction. Possible reasons for this could be variation in the secimen properties and formation of uncounted cracks close to, but outside the observation zone, and could effect the results. Some dispersion in the experimental data could also be caused by randomness in the mechanical properties of the material, effects of the notches at the edges of the specimen on the $0^{\circ}$ outer ply. In addition, the CFRP[1] laminates showed multiple small cracks occurred at the free edges which did not penetrate along the specimen, which could affect the stiffness reduction measurements as well.

\section{Conclusion}

Intralaminar damage behavior and its effects on the mechanical properties of several angle-ply FRP laminates were investigated. CFRP and GFRP laminates with fiber configuration of $\left[\theta_{\mathrm{m}}^{(2)} / \theta_{\mathrm{n}}^{(1)}\right]_{\mathrm{s}}$ were cured by using the autoclave method. In order to study the damage behavior and its effects, the laminates were loaded monotonically and cyclically and cracks observations were carried out. In some angle-ply laminates, artificial cracks were create before the laminates were monotonically loaded, so that higher crack densities could be attained. From monotonic tensile tests, we understand that as the middle off-axis ply becomes thicker, the Young's modulus and maximum tensile stress of the laminates decreases. On the other hand, the differences in off-axis orientations have marginal effects on the stiffness and strength of a laminate. From the cyclic loading results, for CFRP laminates of the same thickness, changes in the off-axis angle from $90^{\circ}$ to $45^{\circ}$, earlier cracking initiation and observed nonlinearity of the stress-strain curve were recorded. Changes in the transverse strain, which reflect the effective Poisson's ratio of the laminate, were larger in laminates with off-axis angle $45^{\circ}$ than in laminates with off-axis angle $90^{\circ}$. For CFRP laminates, it can be observed that first cracks mostly formed and accumulated at free edges. Crack propagation rates in the width direction were dependent on the thickness of the middle ply. In contrast to CFRP laminates, cracks in GFRP laminates formed instantaneously propagating in the width direction. Stiffness in laminates with the thicker off-axis plies reduced more. The experimental data and predictions of the variational analysis are found in good agreement for the Young's modulus of the cracked laminate. Systematic analysis of residual strains due to increasing crack density will be addressed in future publications. 


\section{References}

[1] Hashin, Z. (1985) Analysis of Cracked Laminates. Mechanics of Materials, Vol. 4, No 2: 121-136.

[2] Hashin, Z (1986) Analysis of Stiffness Reduction of Cracked Cross-Ply Laminates. Engineering Fracture Mechanics, Vol. 25, No 5-6: 771-778.

[3] Hashin, Z (1988) Thermal Expansion Coefficients of Cracked Laminates. Composites Science and Technology, Vol. 31, No 4: 247-260.

[4] Vinogradov, V. and Hashin, Z. (2010) Variational Analysis of Cracked Angle-Ply Laminates. Composites Science and Technology, Vol. 70, No 4: 638-646.

[5] Nairn, JA, Shoufeng (1992) The Formation and effect of outer-ply microcracks in cross-ply laminates: A Variational Approach. Engineering Fracture Mechanics, Vol. 41, No 2: 203-221.

[6] Nairn, JA (1992) Microcraking, Microcrack-induced Delamination, and Longitudinal Splitting of Advance Composite Structures. NASA Contractor Report, Vol. 4472:5-71.

[7] Li, S., Hafeez, F., 2009. Variation-based cracked laminate analysis revisited and fundamentally extended. International Journal of Solids and Structures 46, 3505-3515.

[8] Katerelos, D.T.G., Krasnikovs, A., Varna, J., 2015. Variational models for shear modulus of symmetric and balanced laminates with cracks in 90-layer. International Journal of Solids and Structures 71, 169-179.

[9] Bassam, F., Boniface, L., Jones, K., Ogin, S.L., 1998. On the behaviour of the residual strain produced by matrix cracking in cross-ply laminates. Composites Part A: Applied Science and Manufacturing 29, 1425-1432.

[10] Vinogradov V. 2015. Analysis of initial accumulation of matrix cracks in angle-ply laminates. In: Proceedings of 20th International Conference on Composite Materials (ICCM20)., Copenhagen, Denmark. July 19-24 2015. 